\title{
Record of Carpophilus (Ecnomorphus) extensus Grouvelle from Europe with notes on synonymy (Coleoptera: Nitidulidae)
}

\author{
A.G. Kirejtshuk \& A. Herrmann
}

Kirejtshuk, A.G. \& Herrmann, A. 2007. Record of Carpophilus (Ecnomorphus) extensus Grouvelle from Europe with notes on synonymy (Coleoptera: Nitidulidae). Zoosystematica Rossica, 16(2): 251-252.

A specimen of Carpophilus extensus Grouvelle, 1908 has been collected in Northern Germany with a flight intercept trap. This is the first record of this African species for Europe. The lectotype of this species is designated, and synonymy of C. (Ecnomorphus) trapezicollis Kirejtshuk, 1995 with C. extensus is established.

A.G. Kirejtshuk, Zoological Institute, Russian Academy of Sciences, Universitetskaya nab. 1, St.Petersburg 199034,Russia.E-mail:agk@zin.ru, Alexander_kirejtshuk@yahoo.com

A. Herrmann, Bremervörder Straße 123, D-21682 Stade, Germany. E-mail: herrmann@ coleopterologie.de

Carpophilus (Ecnomorphus) extensus Grouvelle, 1908 (see Figure, p. 252)

=C. (E.) trapezicollis Kirejtshuk, 1995, syn. n.

Lectotype of C. extensus (designated here): o", "Amani, Af. Or. All.", "Carpophilus extensus ty. Grouv." (written by A. Grouvelle), "lectotype" (label in collection by Endrödy-Younga), deposited at Museum National d'Histoire Naturelle (Paris).

Type series of C. (Ecnomorphus) trapezicollis from Cameroon, deposited at Deutsches Entomologishes Institut and Zoological Institute of Russian Academy of Sciences.

Other material examined. 1 specimen, Germany, near village Gudow, south of Lübeck, flight intercept trap, between 22.VIII.2004 and 18.IX.2004, leg. Stephan Gürlich, deposited at Zoological Museum of Hamburg University.

Comparison of the listed specimens has shown their conspecifity, though the lateral lobes of the tegmen are slightly longer in the specimen from Germany, as compared to African specimens. Thus, $C$. (E.) extensus is recorded from both western and eastern parts of Equatorial Africa as well as from Central Europe (perhaps, it can live under natural conditions in Central Europe, but scarcely overwinters there).

This species was quite adequately described by Kirejtshuk (1995). It is a member of the subgenus Ecnomorphus Motschulsky, 1858, as it is characterized by the body subflattened, shining or rarely dull; pronotum with gently sloping and usually moderately explanate sides; antennal club usually somewhat loose between antennomeres 9 and 10; mesosternum simple (without isolated median plate in the distal half). C. (E.) extensus is quite distinct among the consubgeners due to its almost straight lateral edges of pronotum narrowing anteriorly from its base. Only some specimens of C. (E.) succisus Erichson, 1843 from Central and South America have somewhat similar pronotal sides, although they are never so convergent anteriorly as those in $C$. (E.) extensus. Besides, the latter species has a larger and darker body, much more convex dorsally, with markedly coarser punctation on the dorsum, much longer penultimate abdominal segment completely exposed from above, and rounded apex of the male pygidium.

The trap in which $C$. extensus was caught in Germany was located in a height of about 10 meters in the top of an old oak tree. A bottle containing a mixture of ethanol, water, glycerol and glacial acetic acid (in proportion $4: 3$ : $2: 1$ ) was attached to the bottom of the trap as killing and preserving liquid. The direct surrounding of the collecting area is agricultural land and gives no direct hints about a possible way of importation of the specimen. In 2005 and 2006, traps have been placed at the same location again, but no more specimens of $C$. extensus were caught.

\section{Acknowledgements}

The authors express their sincere thanks to N. Berti, T. Deuve and A. Taghvian (Museum National d'Histoire Naturelle, Paris). This study of A.G. Kirejtshuk was supported by the Program of Presidium of the Russian Academy of Sciences "Origin and Evolution of the Biosphere" and grant of the Russian Foundation for Basic Research (no. 70400540).

\section{References}

Grouvelle, A. 1908. Coleoptères recoltes dans l'Afrique Oriental Allemande par le Dr F. Eichelbaum. Rev. Entomol. (Caën), 27: 97-126.

Kirejtshuk, A.G. 1995. New taxa of the Nitidulidae (Coleoptera) of the Eastern Hemisphere. Part 5. Trudy Zool. Inst. Ross. Akad. Nauk, 258: 3-50. (In Russian).

Received 15 August 2007 


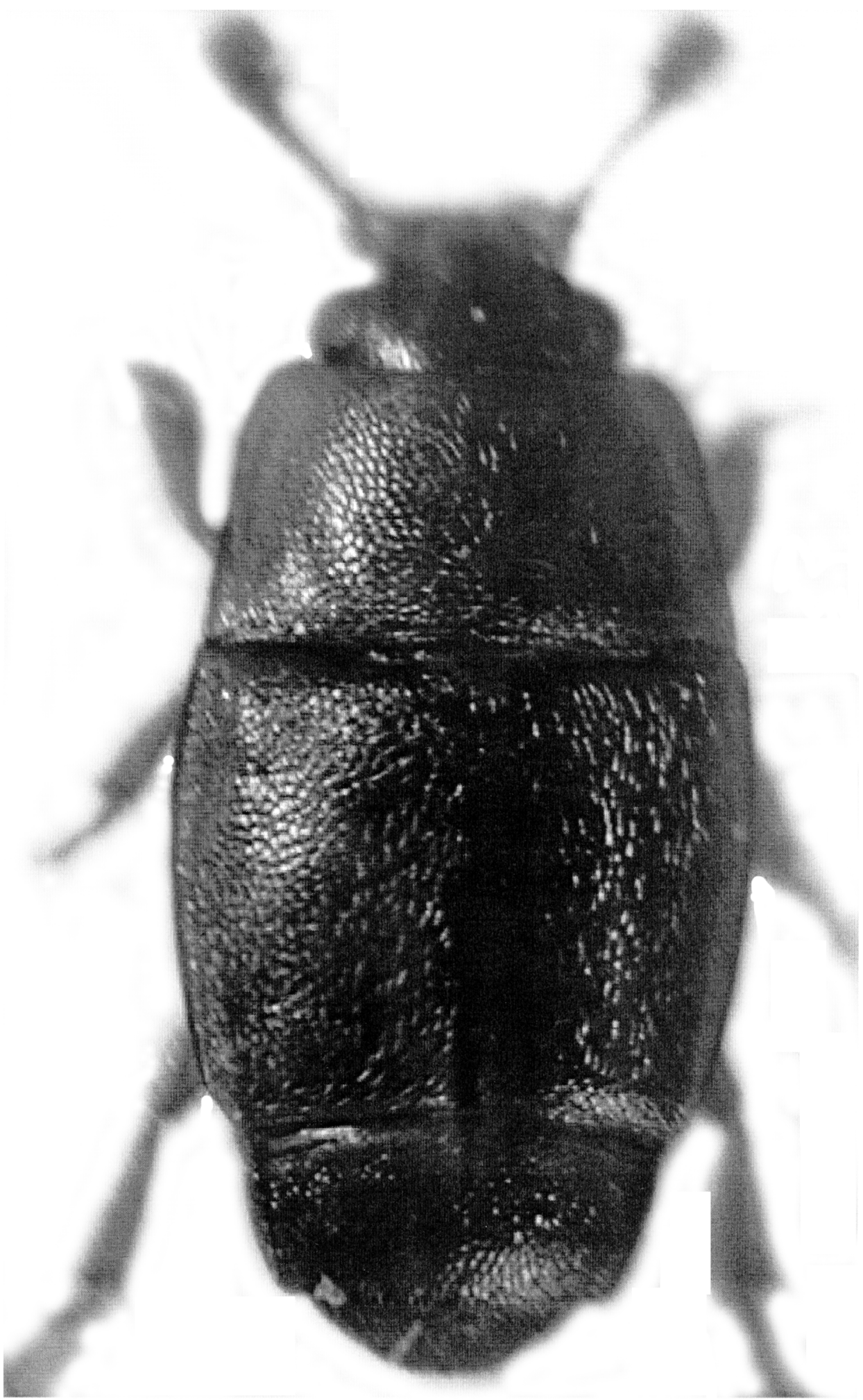

Carpophilus (Ecnomorphus) extensus, specimen of $2.3 \mathrm{~mm}$ from northern Germany, Gudow. 